\section{STOCHASTIC STRENGTH ANALYSIS OF COMPRESSION HEADLESS SCREW}

VOJTECH BAJTEK ${ }^{1}$, KAREL FRYDRYSEK ${ }^{2}$, LEOPOLD PLEVA ${ }^{2}$

${ }^{1}$ VSB - Technical University of Ostrava, Faculty of Mechanical Engineering, Department of Applied Mechanics, Ostrava, Czech Republic

2University Hospital Ostrava, Czech Republic DOI: 10.17973/MMSJ.2020_03_2019133 e-mail: vojtech.bajtek@vsb.cz

This article deals with strength and stiffness analysis of headless screw. This issue was solved in cooperation with engineering industry and doctors. The problem was solved using a stochastic approach, which utilizes the field of random events (simulations), which are applied for determination of input values. The prototype of headless (Herbert) screw Ti4.0/1.4×30/75 was used for solving this problem. Mathematical equations for analytical calculation of the maximal equivalent stress in screw were established. This issue is statically indeterminate problem in compressive and tensile stresses and needs one more equation (i.e. the condition of deformation), which describes relationship between extension of screw and contraction of bone. Resulting values are not defined for one specific model, but the simulation is taking into account a large amount of random samples (specifically $5 \times 10^{6}$ random simulations), which are distributed by bounded histograms. Furthermore, the probabilistic functions of simulated screw were determined. Due to stochastic strength analysis of headless screw, it meets reliability conditions for practical application in osteosynthetic treatment, see [Frydrysek 2016]

KEYWORDS

Headless (Herbert) Screw, Stochastic Analysis, Osteosynthesis, Strength, Histogram, Biomechanics

\section{INTRODUCTION}

The Strength and stiffness analysis of headless screw (i.e. Herbert screw) was solved in cooperation with industry and doctors. There is one specific case, which is described in this text. This issue was solved using a stochastic approach, which utilizes the field of random events (simulations), which are applied for determination of input and output values. It helps to describe real variability of possible results, which depend on chosen distribution function (histograms) and on amount of random simulations, which we include to solution (SBRA method - Simulation-Based Reliability Assessment, direct Monte Carlo method), [Marek 2009]. Fracture of foot metatarsal bone was used for simulation of this specific computational model. However, results represent well also other applications of headless screw. For example, fractures of phalanx, elbow, scaphoid etc. The prototype of headless screw Ti 4.0/1.4×30/7 was used for solving this issue. Screw was delivered by company Medin, a.s. and simulations were solved within the scientific projects.

\section{STOCHASTIC STRENGTH ANALYSIS OF HEADLESS SCREW}

Headless screw Ti 4.0/1.4×30/7 was used for this specific case of fracture of $5^{\text {th }}$ metatarsal [Perry 1992], [Simeckova 2018]. Headless screw is shown on Figure 1. Basic dimensions are written in Table. 1. Diameters $\varnothing \mathrm{D} 1 \mathrm{a}[\mathrm{mm}]$ and $\varnothing \mathrm{D} 1 \mathrm{~b}[\mathrm{~mm}]$ are mean diameters of given threads.

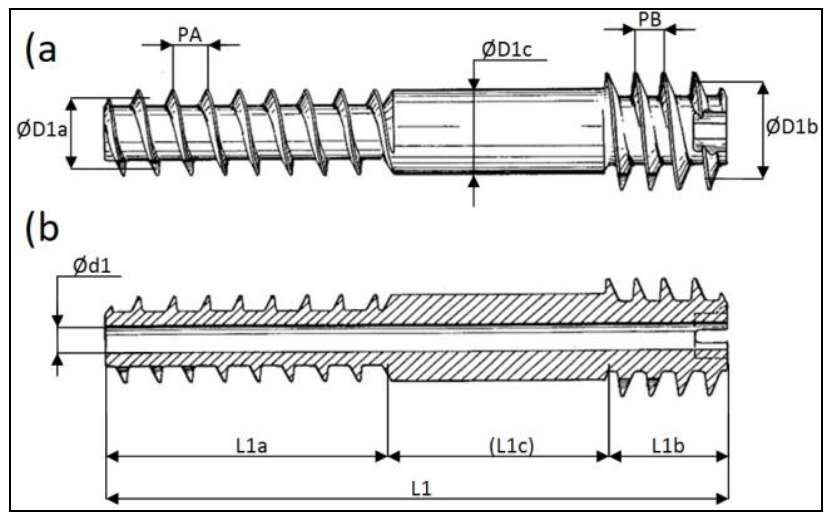

Figure 1. Description of headless screw dimensions, (a Herb. Screw, (b cross- section of screw

\begin{tabular}{|c|c|c|c|c|}
\hline \multicolumn{5}{|c|}{ Headless Screw Ti:4,0/1,1×30/7 } \\
\hline \multirow{2}{*}{ Length [mm] } & L1 & L1a & L1b & L1c \\
\hline & 30 & 7 & 4 & 19 \\
\hline \multirow{2}{*}{ Diameter [mm] } & D1a & D1b & D1c & d1 \\
\hline & 3.3 & 4.7 & 2.5 & 1.4 \\
\hline \multirow{2}{*}{ Thread pitch [mm] } & \multicolumn{2}{|c|}{ PA } & \multicolumn{2}{|c|}{ PB } \\
\hline & \multicolumn{2}{|c|}{1.1} & \multicolumn{2}{|c|}{0.9} \\
\hline
\end{tabular}

Table 1. Table of values of headless screw dimensions (median values)

\subsection{Application of headless screw}

Medical application of headless screw is shown graphically on Figures 2 to 5 . There is description of osteosynthetic treatment of fracture of $5^{\text {th }}$ metatarsal [Manak 2012]. Firstly, Kirschner wire is drilled into bone. This wire helps to implement cannulated headless screw, which will cause the compression of both bone fragments. See Figures 2 to 5 .

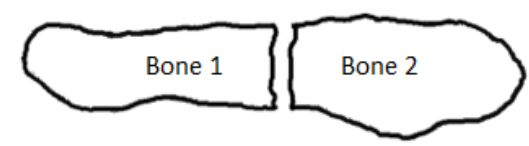

Figure 2. Two parts of broken bone ( $5^{\text {th }}$ metatarsus).

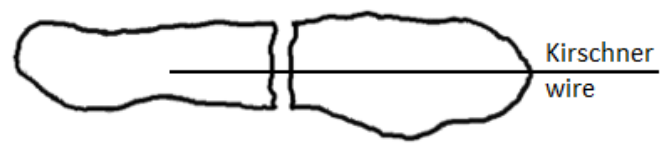

Figure 3 Drilling of Kirschner wire into bone ( $5^{\text {th }}$ metatarsus).

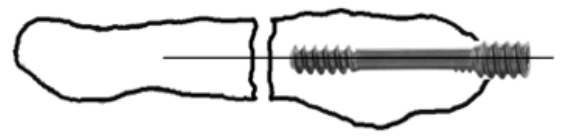

Figure 4. Application of cannulated headless screw ( $5^{\text {th }}$ metatarsus).

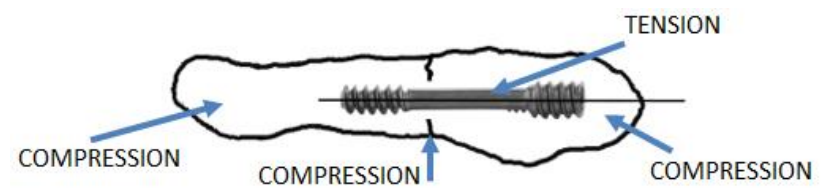

Figure 5. Tightening of headless screw and compression of bone fragments ( $5^{\text {th }}$ metatarsus).

\subsection{Analytical model}

The mathematical equations for analytical calculation of maximal equivalent stress (i.e. von Mises stress) in screw and bone were defined. From mechanics, it is statically 
indeterminate problem in compressive stress. Obtained results come from constant input values. Mathcad software was used for analysis.

Small deformations are presumed so validity of Hooke's law is supposed, too. Isotropic and bulk homogeneous material is considered in this calculation.

The prerequisite for tightening bone fragments to each other is based on the different thread pitch of the headless screw. It means thread pitch PA [mm] must be greater than thread pitch PB $[\mathrm{mm}]$ (i.e. PA > PB), see Figure 1. When bones are in close proximity and headless screw is implemented, then displacement of bone fragments $\Delta s=n \cdot(P A-P B)$ comes from rotation of screw by turn value $n$ [1]. The displacement causes compression and prestress in headless screw. This displacement is marked as "deltaS" $[\mathrm{mm}]$ in text and in equations, see Figure 6.

It was necessary to determine a deformation condition to solve a statically indeterminate tensile and compression problem. The deformation condition describes the relationship between headless screw extension $(\Delta 1[\mathrm{~mm}])$ and shortening of bone fragments $(\Delta 2[\mathrm{~mm}]$ and $\Delta 3[\mathrm{~mm}])$, see Figure 6 . Axial normal force $N F[N]$ was obtained from the solution of statically indeterminate analysis. Normal force NF led to gain maximal stress [MPa] in headless screw and both fragments of bone.

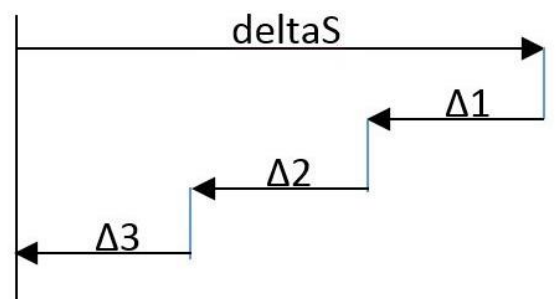

Figure 6. Deformation condition for solving statically indeterminate issue (deltaS=displacement caused by headless screw tightening, $\Delta 1=$ extension of screw, $\Delta 2,3=$ shortening of bone fragments)

\subsection{Stochastic inputs}

Stochastic approach of this solution includes real dispersion and variability of geometry and material properties of headless screw and bone. Input values for headless screw geometry corresponds (are bounded) to normal distribution. Resulting values are not determined for one constant model, but a large amount of random simulations (specifically in this case $5 \times 10^{6}$ random simulations) is simulated.

\section{$2.4 \quad$ Results of stochastic analysis (outputs)}

Equations needed for stochastic solution are presented in [Bajtek 2019]

The relative displacement of the bone fragments is given by difference of pitches of both headless screw threads. Also it is given by number of turns during screw tightening. Final results of displacement "deltaS" are shown on Figure 7.

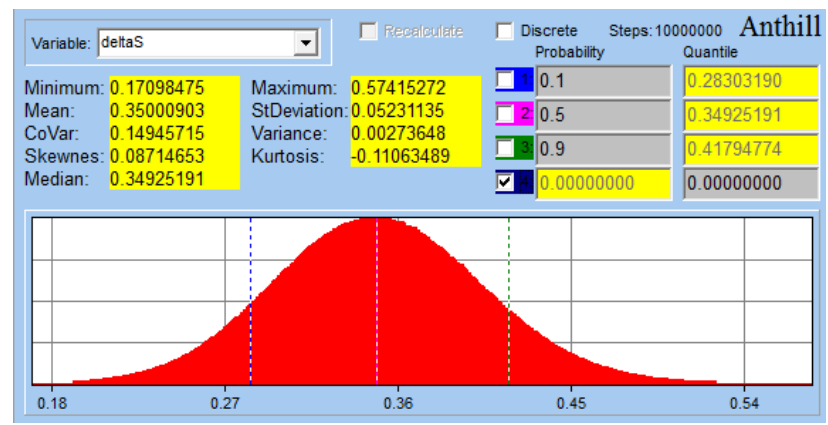

Figure 7. Displacement of bone fragments. DeltaS (mean $=0.350 \mathrm{~mm}$, minimum $=0.171 \mathrm{~mm}$, maximum $=0.574 \mathrm{~mm}$ ) - Anthill software

There is stochastic layout of size of normal force in headless screw Ti 4.0/1.4×30/7 on the Figure 8. This force NF is caused by tightening of screw.

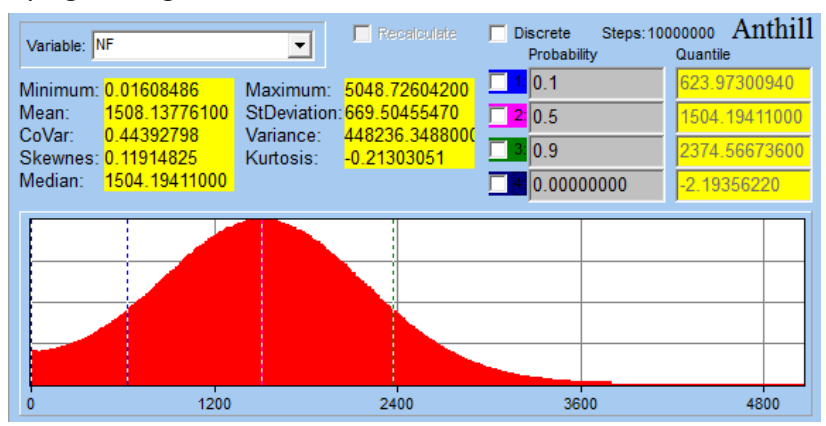

Figure 8. Axial normal force NF in headless screw. NF (mean $=1504 \mathrm{~N}$, minimum $=0 \mathrm{~N}$, maximum $=5048 \mathrm{~N}$ ) - Anthill software

Stochastic layout of compression stress [MPa] in both fragments of bones "Bone1" and "Bone2" can be seen in Figures 9 and 10 .

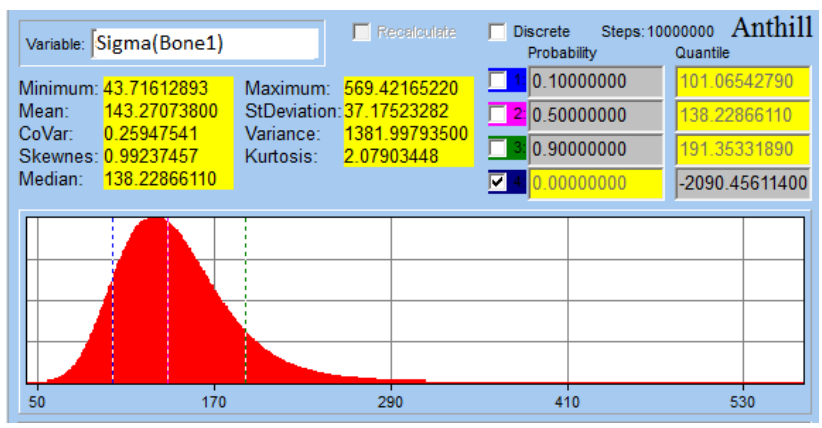

Figure 9. Compression stress Sigma(Bone1) in bone fragment (Bone1). ( mean $=138 \mathrm{MPa}$, minimum $=44 \mathrm{MPa}$, maximum $=569 \mathrm{MPa})-$ Anthill software

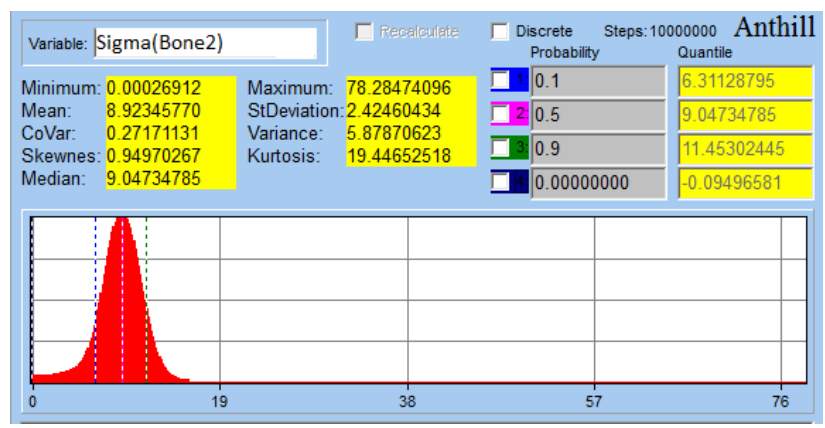

Figure 10. Compression stress Sigma(Bone2) in bone fragment (Bone2). $($ mean $=9 \mathrm{MPa}$, minimum $=0 \mathrm{MPa}$, maximum $=78 \mathrm{MPa})-$ Anthill software

Results of maximal tensile stress in headless screw $\mathrm{Ti}$ 4.0/1.4×30/7 are shown in Figure 11.

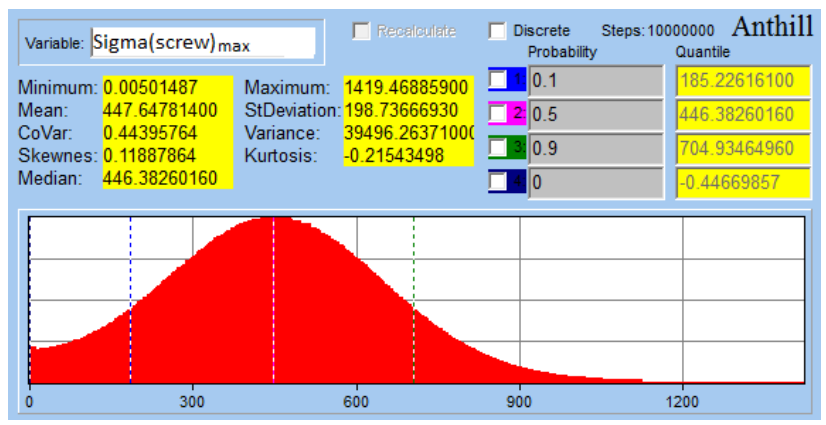


Figure 11. Stress (maximal tensile) in headless screw Sigma(screw) max. ( mean $=446 \mathrm{MPa}$, minimum $=0 \mathrm{MPa}$, maximum = $1419 \mathrm{MPa})-$ Anthill software

Function of screw reliability fRscrew [MPa] is defined in equation (1).

$$
\text { fRscrew }=\operatorname{Re}-\mid \text { Sigma }(\text { screw })_{\max } \mid \text {, }
$$

where $\mathrm{Re}$ is yield strength of screw material [MPa] and Sigma(screw) $\max$ is headless screw maximal stress (see Figure 11).

If fRscrew $>0$, then there are no plastic deformations (i.e. there are elastic deformations) in headless screw. It means, yield strength of material is not exceeded. Otherwise, (fRscrew $\leq 0$ ), there is plastic deformation in headless screw. It is stressed above the yield point, which is unfavorable situation.

Reliability function comes from difference of material yield strength $\operatorname{Re}(\mathrm{Screw})$ histogram and histogram of absolute value of stress, see Figure 13. Probability of achievement of plastic deformation in headless screw is $p(f R s c r e w<0)=0.01$. It means $1 \%$ probability of headless screw plastic deformation, see Figures 12 and 13. Stochastic strength analysis shows, that there is low probability of plastic deformation in headless screw

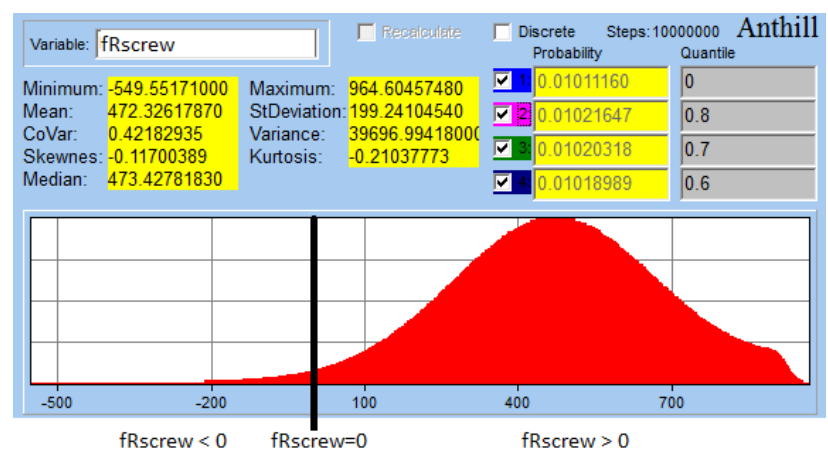

Figure 12. Function of screw reliability fRscrew [MPa] (1D graph of stochastic distribution) - Anthill software

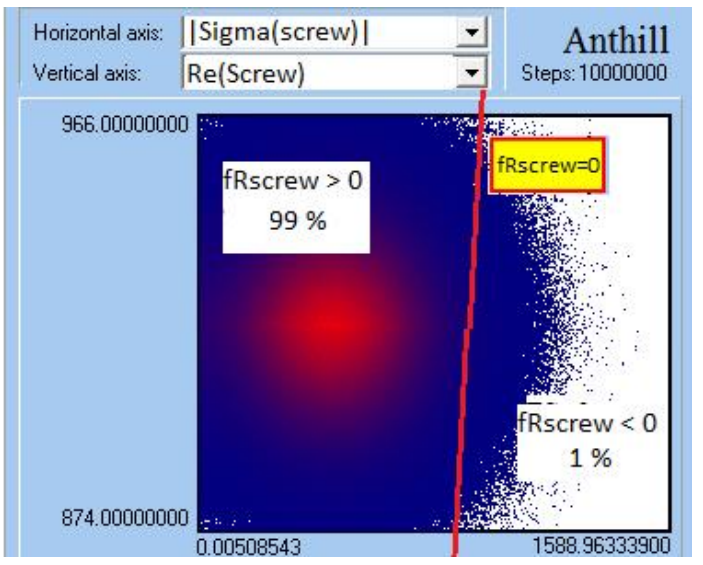

Figure 13. Function of screw reliability, Sigma(screw)max vs. Re(Screw), (2D graph of stochastic distribution) - Anthill software

Stochastic strength analysis of application of headless screw during osteosynthetic treatment of metatarsal bones shows that headless screw meets reliability conditions for practical application. Less common failure of application of headless screw will be mostly caused by bone thread stripping. This conclusion is given by resuts which are seen above. Headless screw itself will not be most likely damaged and can be recommended for clinical practice. Plastic deformations are possible and acceptable in some cases, see Figure 14 [Haspl 2018]

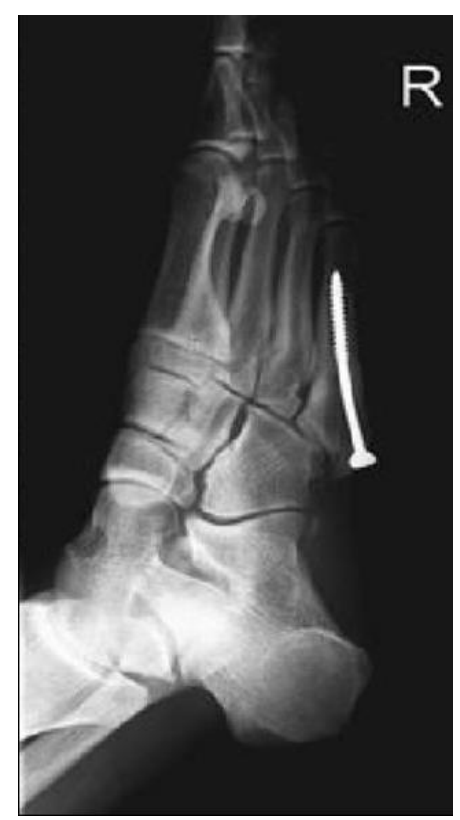

Figure 14. RTG X-ray image of headless screw application - acceptable case of plastic deformation of screw (healed fracture with deformed screw), see [Haspl 2018].

\section{FURTHER DEVELOPMENT OF THE ISSUE}

Laboratory measurements were done to obtain dependencies during tightening of headless screw [Cada 2017]. These curves are influenced by a pair of threads with different pitches. A compressive force is generated due to the tightening of screw inside bone fragments. This force is measured by a tensometric (strain gauge) sensor with a hole. It is possible to messure compressive force between the bone segments by this way. Drawing of experiment is shown in the figure bellow, Figure. 15.

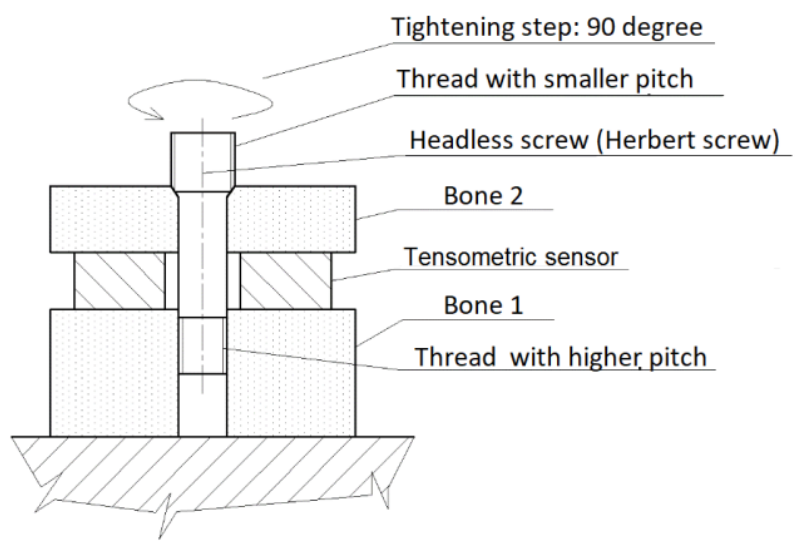

Figure 15. Diagram of experiment

Finite Element (FE) analyses were started too. Real material properties were obtained from CT scans of metatarsal (cooperation with University hospital Ostrava, Ostrava, Czech Republic) and used as input parametres. Mimics Materialise software was used for processing of CT scans. There is simulated bone with FE mesh on Figure 16. Acording to human anatomy, there are 100 different elastic material properties of bone, see Figure 16. Normal forces, stersses and strains in headless screw were determined using FE analysis. These results will be published in the doctoral thesis of the author of this paper (Bajtek 2019) and in following future article. 


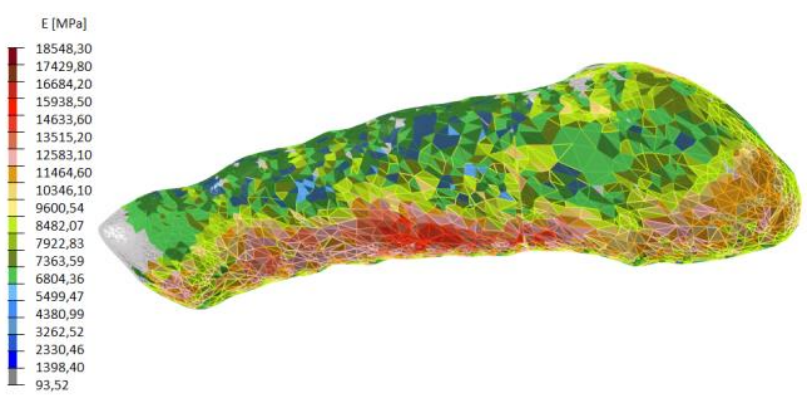

Figure 16. Generated mesh of finite elements. Input for FEM analysis Hypermesh software (i.e. data acquired via Mimics Materialise software).

\section{CONCLUSION}

Strength simulations of the prototype of headless (Herbert) screw were made. These simulations were done in cooperation of Czech partners, i.e. VSB - Technical University of Ostrava, University of Ostrava, Medin, a.s. and University Hospital of Ostrava.

The stochastic analysis method based on Monte Carlo Method was used for solving the issue. This method uses wide variability of real inputs. For example, manufacturing inaccuracies of the screw, variability of bone material properties and others are considered.

The aim of this study was to obtain dependence of internal axial forces and axial stresses in headless screw and bone fragments. These results are found out during osteosynthetic treatment of fractures, specifically application of headless screw. The internal axial force acting in the screw has a median value of $1504 \mathrm{~N}$. This force will be further compared and refined by other methods of solution. All simulations were done as a part of the Ph.D. study at the Department of Applied Mechanics at the VSB - Technical University of Ostrava, [Bajtek 2019]. The results of the simulations will be published in the doctoral thesis [Bajtek 2019].

The article also describes the further development of solutions to the issue.

\section{ACKNOWLEDGMENTS}

The authors gratefully acknowledge the funding from the project SP2019/100 "Use of numerical and experimental modelling in industrial practice", the project reg. no. CZ.02.1.01/0.0/0.0/17_049/0008441 "Innovative therapeutic methods of musculoskeletal system in accident surgery" and the project reg. no. CZ.02.1.01/0.0/17_049/0008407 "Innovative and additive manufacturing technology-new technological solutions for 3D printing of metals and composite materials".

\section{REFERENCES}

[Bajtek 2019] Bajtek, Vojtech. Biomechanics - External and Internal Fixators for Treatment of Various Types of Complicated Bone Fractures. VSB-TU Ostrava

[Cada 2017] Cada, Radek, et al. Analysis of locking Self-Taping Bone Screw for Angularly Stable Plates. Journal of Medical and Biological Engineering, volume 37, issue 4, Pages 612-625, ISSN 16090985

[Frydrysek 2016] Frydrysek, Karel and Vaclavek, Leo. Stochastic computer approach applied in the reliability assessment of engineering structures. Advances in Intelligent Systems and Computing, volume 451, Pages 121-129, ISSN 21945357

[Haspl 2018] Haspl, Miroslav, et al. Clinics in Surgery, Multiple Surgical Treatment of Recurrent Fifth Metatarsal Stress Fracture, 2018, [online]. Volume 3, Article 1925, 26 Feb 2018 Available from

[Manak 2012] Manak, Pavel. and Drac, Pavel. Osteosynthesis and arthrodesis of the skeleton of the hand. Prague: Grada, 2012. ISBN 978-80-247-3873-4. (in Czech)

[Marek 2009] Marek, Pavel, et al. Probabilistic calculations in mechanics. Applied Mechanics 2009, Slovak University of Technology, Pages 37-38, ISBN 978-8089313-32-7

[Perry 1992] Perry, Clayton and Gilula, Louisa. Basic principles and clinical uses of screws and bolts. Orthopaedic Review, volume 21 , issue 6 , Pages $709-716$, ISSN 00946591

[Simeckova 2018] Simeckova, Katerina, et al.. Biomechanics osteosynthesis of the 5th metatarsal with a headless screw. New methods of damage and failure analysis of structural parts, VSB-TU Ostrava, 10-14 September, 2018 $<$ http://www.clinicsinsurgery.com/pdfs_folder/cisv3-id1925.pdf>. Identification code.

\section{CONTACTS:}

doc. Ing. Karel Frydrysek, Ph.D.

VSB - TU Ostrava, Department of Applied Mechanics

17. listopadu 2172/15, Ostrava - Poruba, 70800, Czech Republic,

+420 597323 495, karel.frydrysek@vsb.cz 